Cite as: Jones, M., \& He, V. (2016). Cycles of diversity - An approach towards building diversity acceptance in volunteer organisations. Proceedings of Informing Science \& IT Education Conference ( $I^{n}$ SITE) 2016, 53-57. Retrieved from http://www.informingscience.org/Publications/3459

\title{
Cycles of Diversity - An Approach towards Building Diversity Acceptance in Volunteer Organisations
}

\author{
Michael Jones and Valerie He \\ University of Wollongong, Australia
}

mjones@uow.edu.au; xh029@uowmail.edu.au

\begin{abstract}
Many organisations around the world are beginning to move towards a position of increased diversity in their numbers. There are many ways to look at the issue and achieve satisfactory outcomes. This paper explores an approach which offers strong advantages and benefits for the functional integration of minority groups. Operating on the theoretical principles of Diversity Acceptance and Organisational Inclusive Behaviour, the paper will explore the two cycles of diversity. The first cycle follows a 'vicious' path, where diversity adjustments are not applied or effective. This cycle highlights the problems that occur as a result of increased heterogeneity. The second cycles follows a 'virtuous' path, where diversity adjustments are successful, and the benefits of Diversity Acceptance and Organisational Inclusive Behaviour can be realized. The paper will close with a presentation of the strategies that can be employed to deliver effective diversity adjustments through Diversity Acceptance and Organisational Inclusive Behaviour.
\end{abstract}

Keywords: Diversity, Inclusion, Volunteering.

\section{Introduction}

Stereotypes and behavioural norms around issues such as gender, diversity and minority groups is not unusual in any circumstance, in fact in the public sphere, it is business as usual. A gender analysis of typical news reports in popular media conducted on NVivo

(www.qsrinternational.com) finds a clear divergence of words associated with reports about women versus men with men being associated with terms like: take; independence; direction; play and women associated with a different set of terms like: love; feminine; love; open; nurturing; emotions; heart - see Table 1.

Social change is taking place in all forms of organisation to embrace diversity, reconciling the old stereotypes, assumptions, and biases and leading to a new paradigm of operational harmony around the principles of Diversity Acceptance. Diversity Acceptance (DA) shifts the focus of di-

Material published as part of this publication, either on-line or in print, is copyrighted by the Informing Science Institute. Permission to make digital or paper copy of part or all of these works for personal or classroom use is granted without fee provided that the copies are not made or distributed for profit or commercial advantage AND that copies 1) bear this notice in full and 2) give the full citation on the first page. It is permissible to abstract these works so long as credit is given. To copy in all other cases or to republish or to post on a server or to redistribute to lists requires specific permission and payment of a fee. Contact Publisher@,InformingScience.org to request redistribution permission. versity, so that instead of viewing differences as being negative - barriers to overcome, they are seen as strengths which create value and improve flexibility. A DA focus allows each individual to contribute in their own unique way. Previous studies (Eriksen \& Gill 2010; Eriksen 2012; Eriksen \& Ditrich 2015; Mclennan, Paton \& Beatson 2015) have focused on studying the benefits of a 'gender-balanced' or 'gender-sensitive'

Editor: Eli Cohen

Submitted: February 21, 2016; Revised: March 7, 2016; Accepted: March 11, 2016 
environment for bushfire brigade volunteers. These studies are helpful in improving the level of diversity acceptance, yet not sufficient enough to represent an holistic scope. This current research plans to increase the depth of Diversity Acceptance through the theoretical framework of Organisational Inclusive Behaviour.

Table 1: Top 5 independent gender-based descriptors - analysis from newspaper reports.

\begin{tabular}{|c|c|}
\hline $\begin{array}{c}\text { Words more commonly } \\
\text { associated with MEN }\end{array}$ & $\begin{array}{c}\text { Words more commonly } \\
\text { associated with WOMEN }\end{array}$ \\
\hline TAKE & LOVE \\
\hline PLAY & OPEN \\
\hline USE & FEMININE \\
\hline INDEPENDENCE & FEELINGS \\
\hline SEE & NURTURING \\
\hline
\end{tabular}

Organisational Inclusive Behaviour (OIB) has been found to be at the core of current diversity efforts (Broadnax 2010; Miller 1998; Rangarajan \& Black 2007; Riccucci 2002; Wise 2002). Inclusion is an organisational practice and goal stemming from the sociological notion of inclusiveness. Inclusiveness is the coupling of personal effort with political action to create inclusion practices in which different groups or individuals with different backgrounds (like origin, age, race and ethnicity, religion, gender identity, etc.) are culturally and socially accepted and welcomed, and above all, treated equally.

Organisations that implement diversity management programs largely do so in response to pressure from legislative directives, and this usually takes a quantitative approach to try and 'balance the numbers'. However, diversity management programs will not be successful if they are unable to truly value the diversity employees bring to their workplace (Pless \& Maak 2004). Inclusion goes beyond diversity management where it creates "an organizational environment that allows people with multiple backgrounds, mindsets and ways of thinking to work effectively together and to perform to their highest potential in order to achieve organiational objectives based on sound principles" (Pless \& Maak 2004, p. 130). Research has shown that there is a relationship between levels of inclusion and job commitment and performance (Miller, 1998; Pless \& Maak, 2004; Shore et al., 2010).

Organisations which are unable to leverage the positives of DA and OIB can easily fall into a spiralling cycle of social decline. This is referred to here as 'Vicious Cycles'. There are four elements to these vicious cycles which create a cycle of slow, but perpetual decline. These elements commence with solidarity, moving inexorably to common purpose, then espoused values, then concealment.

\section{The Four Phases of the Vicious Cycle}

1. Solidarity. In the first phase, a volunteer culture is created which, through influences of homophilly and social contagion, attracts people who share similar values. As people tend to be similar, they think along similar lines and share similar expectations. For example an unpleasant comment about a female co-worker may be dismissed as a joke, and accepted by all. At this stage the organisation begins to lose its flexibility and innovation. A system of social expulsion forms where people - new volunteers - who join are not socialised quickly or smoothly and diversity is inadvertently discouraged. 
2. Common Purpose. In phase two of the cycle, people function according to the requirements of the majority - the common purpose. The core tasks begin to take precedence and people are valued by their ability to perform and comply according to the criteria around this common purpose. In volunteer fire brigades, this might be the person's performance as a firefighter, rather than that person's ability as a leader. Key criteria for success and recognition stem from this common purpose and promotion and training opportunities increasingly rely on a person's fit with the common purpose. As a result subtle changes begin in terms of attraction, recruitment and retention. A culture, which begins to preclude options for diversity, is further reinforced.

3. Espoused Values. As phase three begins, the volunteer cohort forms a new culture which may begin to contradict the espoused values of the organisation, especially in terms of diversity and acceptance. A narrow, blinkered approach develops in regard to thinking and problem-solving. Many of the problems associated with Group Think begin to manifest such as self-censorship and reinforcement. These all work to reinforce the current status-quo, with strong pressure for everyone to conform. At this stage new members begin to self-expel. They see existing volunteers as being different 'not like me' and realise prior to the socialisation stage that they are not going to fit it. This is the point where members of minority groups will not stay, or may never even attempt to join.

4. Concealment. During this phase explicit and implicit pressure is placed on members to conceal acts of discrimination. Acts are at first ignored, then they are tolerated, then they become normalised, and then concealed. This leads to increased heterogeneity, and build barriers to diversity of any kind.

This vicious cycle continues, and it becomes more entrenched as it progresses.

\section{The Four Phases of the Virtuous Cycle}

A way forward for organisations to overcome the problems associated with vicious cycles is to embrace Diversity Acceptance and Organisational Inclusive Behaviour. By becoming more aware of the strengths of increased diversity, the organisation can embrace a more tolerant culture through the benefits of the four phases of the Virtuous Cycle. These are Cost, Creativity, Flexibility and Community. These phases work to incorporate and leverage the strengths that can be realized by positively engaging a diversified workforce.

1. Cost. It is generally recognised that volunteer organisation operate in a competitive environment, and the commodity for which they all compete is the volunteer. Volunteers have a choice, they can volunteer for a host of other volunteer organisations in the same sector, they can volunteer in other sectors, and they can choose not to volunteer at all. The first phase of the virtuous cycle acknowledges this and posits that volunteers face an opportunity cost when they choose to invest their time with their chosen organisation. There is also an opportunity investment for the organisation which achieves functional diversity acceptance. First, the resource-pool from which volunteers are drawn becomes bigger as the door is thrown open to a larger demographic of volunteers. Second, organisations which are able to successfully integrate minority groups early will build competitive advantage, and will attract even larger numbers of volunteers from these diverse backgrounds. The same forces which create narrowed tolerances - homophilly and social contagion - also work to attract and retain new volunteers from minority groups. For example, if an organisation was able to increase the number of Asian volunteers who were comfortably integrated, then more Asian volunteers would be attracted to join and would feel compelled to stay. 
2. Creativity. Organisations which involve greater diversity in their operations and planning invite different opinions to the table. This is bolstered by a range of diverse perspectives, variety in individual skills and experiences, and different approaches to problem solving and decision making. These combine to increase creativity and innovation, and to enhance critical analysis and 'Devil's advocacy'.

3. Flexibility. With an increase in diversity, the organisational system becomes more resilient and more flexible. The operational controls become less rigid, and instead become more organic and fluid. Increased fluidity leads to faster and more effective reactions to environmental change. Other, more practical, benefits of diversity in this phase are increases in availability and performance. For example, women are statistically more available to volunteer during the day. Ethnic and national celebrations often occur during different times of the year, which also boosts availability.

4. Community. There are clear benefits resulting from increased diversity at the community level. First, increased diversity increases community integration and representation. Minority elements of the community are better understood and better cared for. Second, through increased diversity, the organisation is able to build and sustain wider and stronger community relationships which lead to increased moral, social and fiscal support.

This virtuous cycle continues. The benefits lead to increased attraction, engagement and retention of more volunteers across a broader cross-section of the community.

This paper will present the research around this framework, and will extend a discussion around possible strategies to create and enhance Diversity Acceptance and Organisational Inclusive Behaviour in volunteer organisations.

The results of this research will be presented in the next Informing Science Conference - InSITE 2017 in Vietnam.

\section{References}

Broadnax, W. (2010). Diversity in public organizations: A work in progress. Public Administration Review, 70,177-179.

Eriksen, C. (2012). Women in leadership: Contextual dynamics and boundaries. Gender, Place \& Culture, 19(3), 398-400.

Eriksen, C., \& Ditrich, T. (2015). The relevance of mindfulness practice for trauma-exposed disaster researchers. Emotion, Space and Society.

Eriksen, C., \& Gill, N. (2010). Bushfire and everyday life: Examining the awareness-action "gap" in changing rural landscapes. Geoforum, 41(5), 814-825.

McLennan, J., Paton, D., \& Beatson, R. (2015). Psychological differences between south-eastern Australian householders who intend to leave if threatened by a wildfire and those who intend to stay and defend. International Journal of Disaster Risk Reduction, 11, 35-46.

Miller, F. (1998). Strategic culture change: The door to achieving high performance and inclusion. Public Personnel Management, 27(2), 51-160.

Pless, N., \& Maak, T. (2004). Building an inclusive diversity culture: Principles, processes and practice. Journal of Business Ethics, 54(2), 129-147.

Rangarajan, N., \& Black, T. (2007). Exploring organizational barriers to diversity: A case study of the New York State Education Department. Review of Public Personnel Administration, 27(3), 249-263.

Riccucci, N. (2002). Managing diversity in public sector workforces. New York: Westview Press. 
Shore, L., Randel, A., Chung, B., Dean, M., Holcombe Ehrhart, K., \& Singh, G. (2010). Inclusion and diversity in work groups: A review and model for future research. Journal of Management, 37(4), 12621289.

Wise, L. (2002). Public management reform: Competing drivers of change. Public Administration Review, 62(5), 556-567.

\section{Biographies}

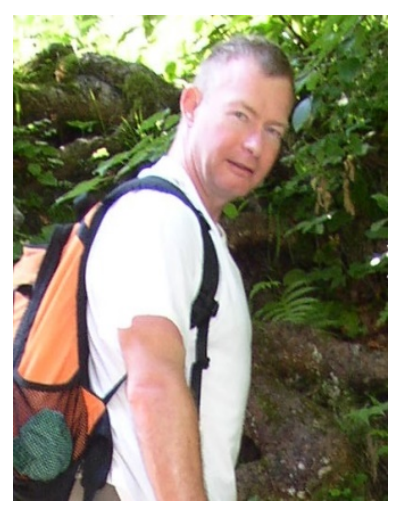

Michael Jones (BComm (hons), PhD.) has been an academic teaching and researching in areas of organization, business and management for fifteen years. Michael has developed research interests in the following areas: organizational psychology and behavior - looking at commitment and motivation and group dynamics. Michael also has research strengths in areas of qualitative analysis and has written several papers on various qualitative methodologies and methods. Michael is interested in research areas such as doctoral studies, organizational culture, and motivation and commitment. Michael is a co-investigator on a major research project exploring retention and engagement in Emergency Management Agencies.

Michael is a member of the Australia and New Zealand Academy of Management, the Australian Human Resources Institute, and the Industrial Relations Society of Australia

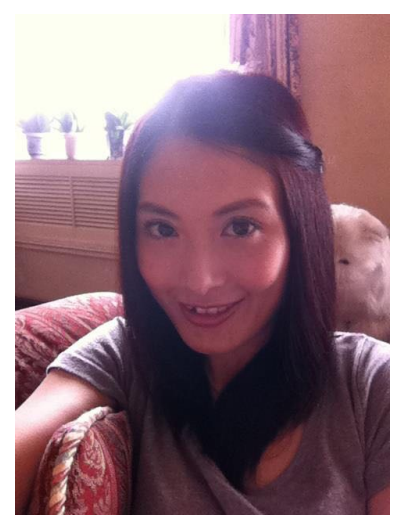

Valerie He is a PhD student and a tutor in the Sydney Business School, University of Wollongong with a specialisation in Organisational Behaviour. She is interested in Gender and Diversity related issues. More specifically, her work explores how Social Inclusion Theory enhances the level of the Acceptance of Diversity within Emergency Management Agencies (EMAs). 